\title{
Study on the Treatment Process of Wastewater from Cephalosporin Production
}

\author{
Haixia Duan (Corresponding author) \\ School of Equipment Engineering, Shenyang Ligong University, Liaoning, Shenyang 110186, China \\ E-mail:d_h_x@163.com
}

\begin{abstract}
Wastewater from cephalosporin production with high bio-toxicity is hard to degrade, and could cause great harm to environment and human being. In the present paper, wastewater from cephalosporin production was processed with biochemical treatments as follows: hydrolytic acidification- Up-flow Anaerobic Sludge Bed(UASB)-Sequencing Batch Reactor Activated Sludge Process(SBR)-biological activated carbon process(BAC). Among them, hydrolytic acidification could efficaciously enhance the biodegradability of wastewater, and greatly increase effects of the subsequent anaerobic-aerobic treatment. The final BAC process could effectively eliminate chemical oxygen demand (COD) and chroma of wastewater treated by aerobic treatment, where COD attained below $100 \mathrm{mg} / \mathrm{L}$ and chroma was 40. Therefore, wastewater after the previous treatments basically conformed to the discharge standard of " Integrated wastewater discharge standard "(GB8978-1996).
\end{abstract}

Keywords: Wastewater from cephalosporin production, Hydrolytic acidification, UASB, SBR, Biological activated carbon

\section{Introduction}

Wastewater from cephalosporin production has complicated components, where organic substances and soluble or colloid solid substances are all at a high level with a great deal of suspended matter, and $\mathrm{pH}$ value varied often, contains biological toxicity substances of unbiodegradable and bacteriostatic antibiotics. In the present paper, wastewater from cephalosporin production was processed with biochemical treatments as follows: hydrolytic acidificationUASB-SBR-BAC process, which guaranteed that wastewater basically conformed to the discharge standard of " Integrated wastewater discharge standard "(GB8978-1996).

\section{2. wastewater quality and outlet requirements}

Wastewater was sampled from a pharmacy factory of Liaoning Province. Relative data was listed in detail in Table 1.

\section{Experimental section}

\subsection{Methods}

(1) Determination of $\mathrm{pH}$ value: glass electrode method;

(2) Determination of chroma: dilution multiple method;

(3) Determination of COD: potassium dichromate method $\left(\mathrm{COD}_{\mathrm{Cr}}\right)$;

(4) Determination of BOD: five-day biochemical cultivation

\subsection{Schematic diagram of processes}

Organic glass cylinder with the height of $100 \mathrm{~cm}$, inner diameter of $10 \mathrm{~cm}$ and effective volume of $6 \mathrm{~L}$ was used as hydrolytic acidification pool. UASB reactor with the height of $150 \mathrm{~cm}$, inner diameter of $8 \mathrm{~cm}$ and effective volume of $6 \mathrm{~L}$, was kept at constant temperature of $37^{\circ} \mathrm{C}$ by jacket water bath adjusted by temperature-control relay and heater. Each vessel was undertaken at a manner of continuous influent, water flew into hydrolytic acidification cylinder and UASB reactor through the bottom feed inlet and flew out from the top. Biogas resulted from UASB reactor was collected by gas trap hood.

\subsection{Hydrolytic acidification}

Using hydrolytic and acid-producing bacteria reactions, undegradable organic substances were decomposed into biodegradable matter with small molecule, which further enhanced the biodegradability and thus decreased the charge of following processes. 


\subsection{UASB reaction}

Basic structure of UASB reactor was mainly composed of sludge bed, sludge suspension layer, precipitate zone, three-phase separator and intake system, and granular sludge in reaction zone was the key of this reactor(Hu, 2002, PP. 159-166). It is a new type and high effective wastewater treatment equipment, which altered the traditional and laggard treatment of anaerobic fermentation, and have novel insight in the design of inlet manner, influent distribution system, agitated mixing and three-phase separator and intake system, and thus could be regarded as an ideal equipment for dealing with wastewater of high, medium and low pollution level. During the performance process, wastewater flew from the reactor bottom evenly through influent distribution system, and flew upward by reaction zone(sludge zone) to three-phase separation zone(gas, liquid and solid), and finally into the precipitate zone of UASB upside. Sludge in the mixed solutions returned to reaction zone from precipitate zone to three phase separation zone by gravity, and the resultant biogas discharged out of the reactor through collecting chamber by pipeline. No mechanical stirring device existed in UASB system, and slurry mixture was undertaken through the uprising and agitating of biogas resulted from flow elevation and treatment processes. Usually, filler was not necessary, and thus UASB system has a simple structure and was easy to maintain.

\subsection{SBR trial}

SBR method, namely sequencing batch reactor, is a regeneration and modification of early filling-and-emptying reactor(Irvine, 1985). The obvious predominance(Peng, 1993, PP. 29-31) of SBR includs as follows: simple technological process, low cost of capital construction and performance; reaction phase is an ideal plug flow process with strong impetus resulted from biochemical reaction and good efficacy; flexible performance manner, good effect of deamination phosphorus removing, and optimal technology for preventing sludge from swelling; resistance to shock loading, and good capability of dealing with toxic or high concentration organic wastewater. SBR was used as subsequent process of anaerobic treatment, in order to assure that the whole effects of system attained the discharge standard. SBR reactor was a cylinder made of $5 \mathrm{~mm}$ organic glass with total volume of $4.5 \mathrm{~L}$, diameter of $140 \mathrm{~mm}$ and effective height of $293 \mathrm{~mm}$. Aerobic sludge sampled from secondary sedimentation tank of a sewage treatment factory was cultured and acclimated in SBR reactor. 8d later, system performance was basically stable, and the color of sludge appeared deep tan with larger floccule, clear margin and better settling property, which indicated that sludge culture had succeeded. If water inflow was too strong, heterotrophic bacteria in reactor would propagated largely due to sufficient nutrition, while nitrobacteria propagated slowly with small specific growth rate, and accounted for less and less proportion in sludge. Moreover, both bacteria would compete for the substrates and dissolved oxygen, which had inhibitory effect on the generation of nitrobacteria. Therefore, each water inflow should not be above $1.5 \mathrm{~L}$, and under such situation, sludge load of reactor was $0.40 \mathrm{kgCOD} /(\mathrm{kgMLSS} \cdot \mathrm{d})$, and COD removal was $80 \% \sim 85 \%$. Results were depicted in Figure 4.

\subsection{BAC trial}

BAC technology used activated carbon with huge specific surface area and developed void structure as carriers for aggregation, propagation and growth of microorganisms, and under the condition of moderate temperature and nutrition, exerted microbiological degradation simultaneously. Such water treatment technology was also called BAC method. Interaction of BAC granule, microorganism and water pollutants (matrix) and dissolved oxygen was involved in the process of wastewater treatment by BAC. From micro perspective, synergistic effect of BAC adsorption and microbiological degradation was not ordinary superposition of both (Woo, 1997, PP. 21-28).

In the present paper, adsorption capacity of BAC was investigated, where granule fragmentary carbon with high adsorption capacity for organic substances was selected as biological carrier, meanwhile diluted pig manure sludge was undertaken to aerobic acclimatization and culture in lab scale, which was applied as biological source to prepare BAC for investigation. 5d later, through the observation of microscope, a layer biofilm was coated in the surface of BAC, which indicated that preparation of BAC has tended to be mature and could be undertaken to treat with wastewater from cephalosporin production.

Wastewater after processes of hydrolytic acidification- UASB-SBR was added to BAC column, in a manner of lower inlet and upper outlet, influents and effluents COD, chroma and removal was presented in Figure 5.

Results showed that BAC advanced treatment could effectively eliminate the COD and chroma of wastewater treated by aerobic treatment, where COD attained below $100 \mathrm{mg} / \mathrm{L}$ and chroma was 40.

\section{Conclusions}

In the normal process of reactor, COD removal of hydrolytic acidification and UASB reactor effluents was kept $36 \% \sim 55 \%$ and $80 \% \sim 90 \%$, respectively. Sludge load of SBR reactor was $0.40 \mathrm{~kg}$ COD/ $(\mathrm{kgMLSS} \cdot \mathrm{d})$, and COD removal was $80 \% \sim 85 \%$. BAC advanced treatment could effectively eliminate the COD and chroma of wastewater treated by aerobic treatment, where COD attained below $100 \mathrm{mg} / \mathrm{L}$ and chroma was 40 . Therefore, wastewater basically conformed to the discharge standard of "Integrated wastewater discharge standard"(GB8978-1996). 


\section{References}

$\mathrm{Hu}$, J.C., et al. (2002). Theory and technology of wastewater anaerobic treatment. Beijing: China construction press, 159-166.

Irvine, R.L., et al. (1985). Teehnology Assessment of Sequeneing Bateh Reaetors. U.S.Environ. Pro.Ageney.

Peng, Y.Z. (1993). Five advantages of SBR method. China Water \& Wastewater, 9(2):29-31.

Woo, H.K., et al. (1997). Pilot plant study on ozonation and biological activated carbon process for drinking water treatment. Wat.Sci.Tech, 35(8): 21-28.

Table 1. Wastewater original quality and outlet requirments

\begin{tabular}{|c|c|c|c|c|c|}
\hline Indices & $\mathrm{pH}$ & $\mathrm{COD} / \mathrm{mg} / \mathrm{L}$ & $\mathrm{BOD} / \mathrm{mg} / \mathrm{L}$ & $\mathrm{SS} / \mathrm{mg} / \mathrm{L}$ & Chroma \\
\hline Measured value & 5.3 & 7230 & 595.1 & 5890 & 850 \\
\hline Outlet requirments & $6 \sim 9$ & 100 & 30 & 70 & 50 \\
\hline
\end{tabular}

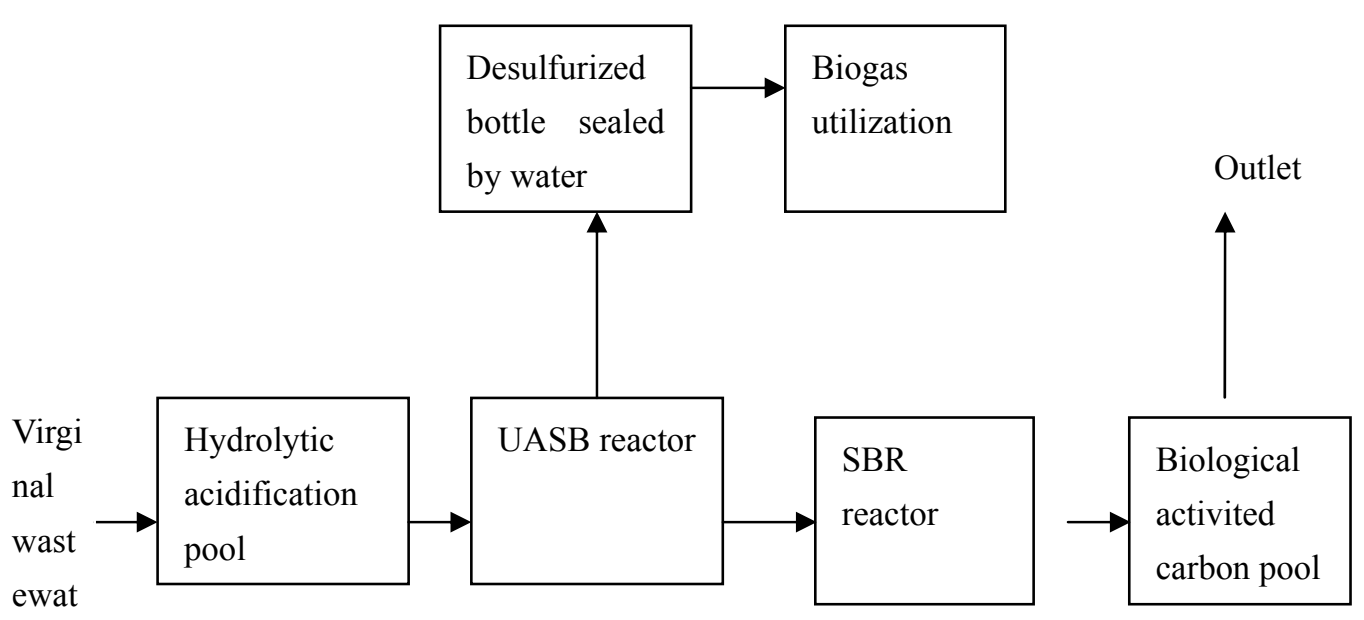

Figure 1. Schematic diagram of processes

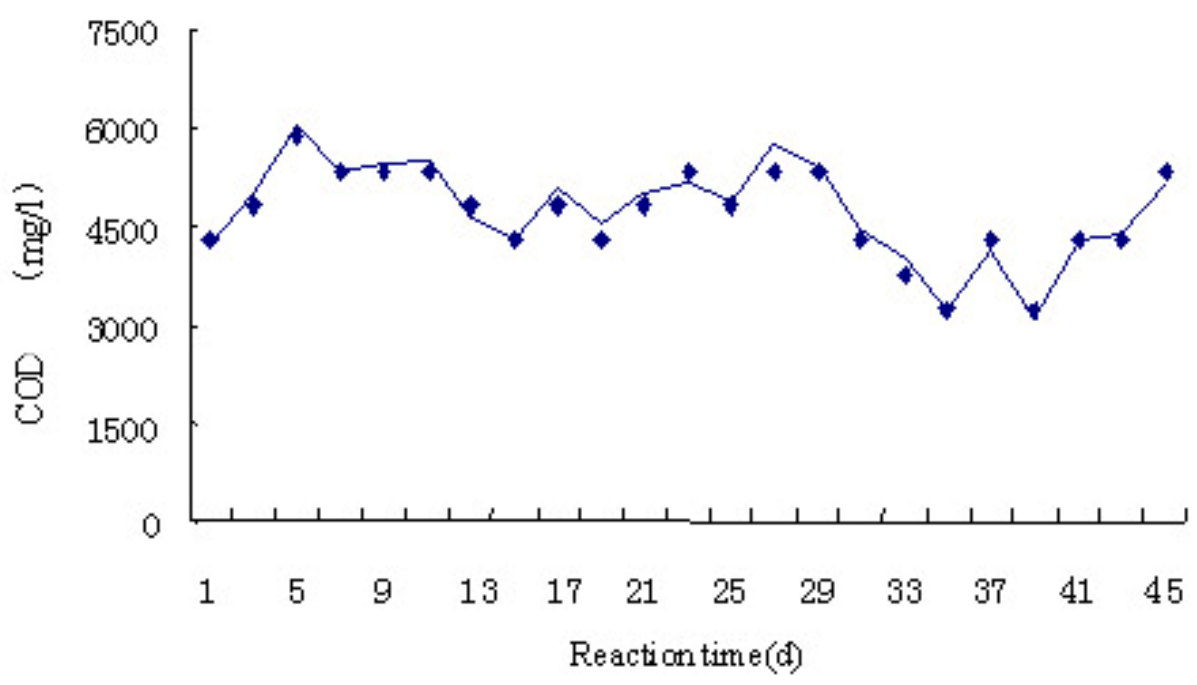

Figure 2. Changing curves of COD in effluents of hydrolytic acidification pool 


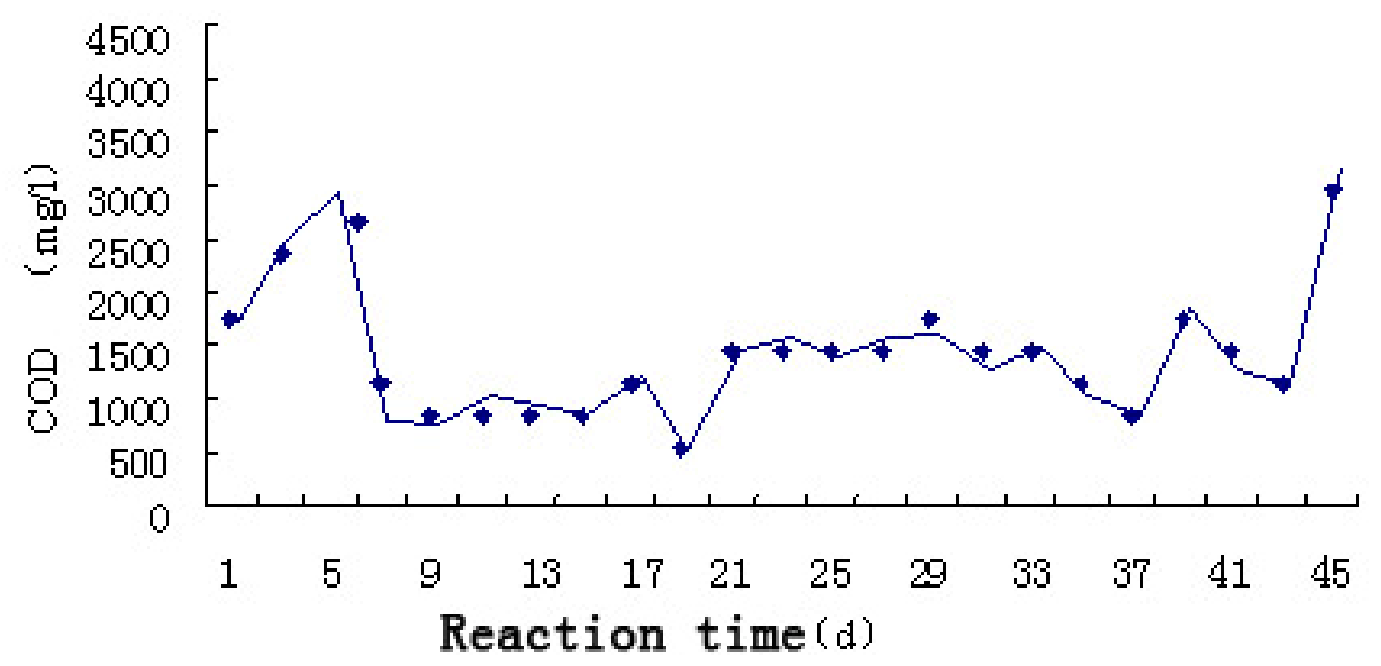

Figure 3. Changing curve of COD in SBR effluents

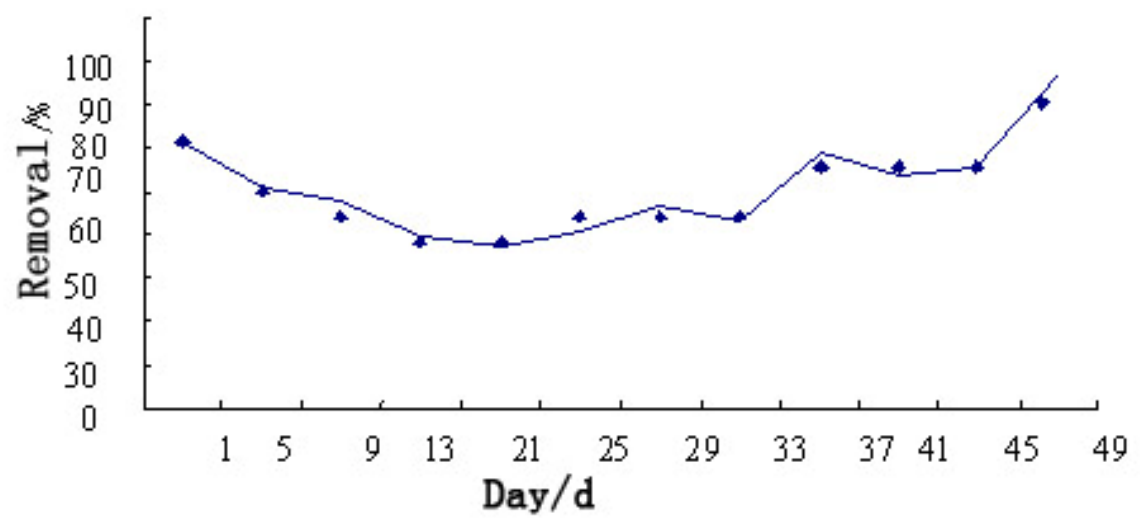

Figure 4. Changing curve of COD in SBR effluents

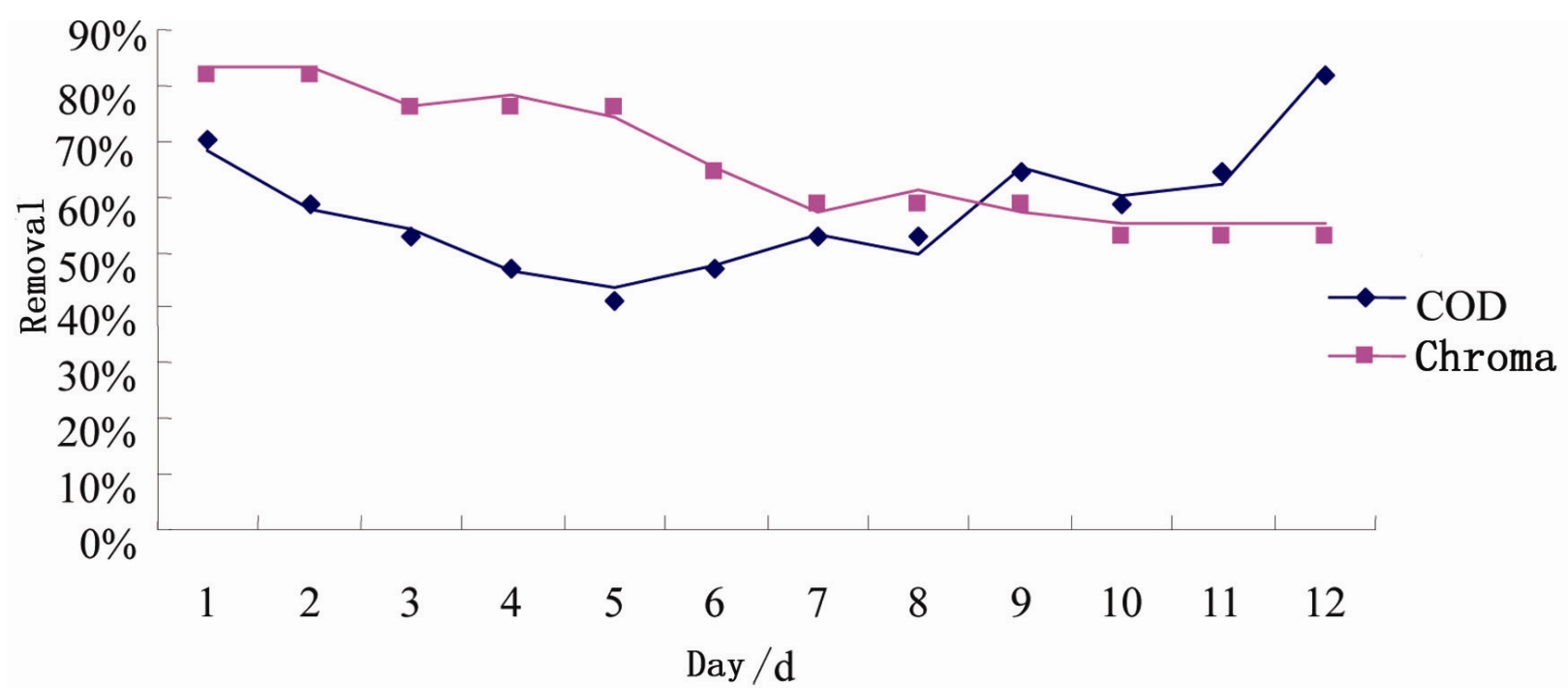

Figure 5. COD and chroma removal of BAC column 